\title{
Application of PCR for Surveillance of Natural Foci of Especial Dangerous Pathogens
}

\author{
Oksana Semenyshyn*, Oksana Velychko, Liliya Vasiunets, Lesya Hatsiy, Iryna Kulish \\ and Oleh Kogut
}

laboratury of EDP, State Institution Lviv Oblast Laboratory Center of Ukraine of the Ministry of Health of Ukraine, Lviv, Ukraine

\section{Objective}

Study the advantages of using the PCR method for monitoring of natural foci within the EDP surveillance system.

\section{Introduction}

Natural foci of especially dangerous pathogens (EDP) (tularemia, leptospirosis, anthrax, tick-borne infections) are known in Lviv oblast for more than 50 years. An integral part of the epidemiological surveillance of these infections is the monitoring of environmental objects that can detect the circulation of pathogens in natural biotopes. Identification and studying of the activity of natural foci of EDP in the territory of Lviv oblast in previous years was conducted using classical laboratory and epidemiological methods

\section{Methods}

Since 2015 in the EDP laboratory are conducted investigations of field materials (mouse-like rodents, ixodic ticks, gray rats, surface water bodies, wild birds dungs, soil) during the monitoring process of the EDP natural foci. From 2015 to 2017 samples of field materials were investigated in order to identify specific DNA regions of causative agents of tularemia, anthrax, leptospirosis, Q-fever, Lyme borreliosis, etc., using the «Primer designTM genesig», «GENEKAM Biotechnology AG», «MO BIO Laboratories, Inc», «Analytic Jena AG» kits, which were provided within the Cooperative Biological Engagement Program (CBEP), and «Amplisens» kits. During this period samples were analyzed from 299 mouse-like rodents, 7325 ixodic ticks, 128 open water reservoirs, 51 wild birds dung, 92 soil samples and 17 gray rats.

In addition, enzyme-linked immunosorbent assay (ELISA) was used. For immunoserological monitoring selected serum samples of 80 people living in enzootic territories were used. Currently, 40 human samples were investigated for the presence of $\operatorname{IgM}$ and $\operatorname{IgG}$ antibodies using the "Serion ELISA classic Francisella tularensis IgG/IgM".

\section{Results}

According to the results of the research that was conducted in previous years it was revealed that in the territory of Lviv oblast there are stable natural foci of tularemia, leptospirosis, tick-borne infections (Lyme borreliosis, tick-borne encephalitis) present. The main reservoirs of pathogens are 5-6 species of small mouse-like rodents and gray rats who are carriers of two dominant species of ixodic ticks. Live cultures of tularemia and leptospirosis were isolated from these types of reservoirs and carriers and positive results of immunoserological analysis were found. Tularemia antigen was detected in $29.2 \%$ of ticks samples (D. reticulatus mainly), causative agents of Lyme borreliosis D. reticulatus was detected in $17.3 \%$ of ticks and I.ricinusin was present in $8.0 \%$ of ticks. During the serological investigation of mouse-like rodents antibodies against F.tularensis were detected in $6.5 \%$ of samples, antibodies against leptospira in $6.7 \%$, and antibodies against borrelia from $14.6 \%$ to $27.7 \%$.

During the monitoring period of burial places of animals killed from anthrax on the territory of the oblast where classical laboratory methods were used, B.anthracis was not detected. However, due to the ability of the pathogen to maintain its pathogenic properties for a long time, monitoring of such areas will be relevant in the future.

According to analysis of mouse-like rodents, ticks, samples of surface water bodies, wild birds dung, soil and gray rats were received $3.18 \%$ positive samples that confirmed the presence of F.tularensis, $9.74 \%$ positive samples of pathogenic Leptospira spp, $20.75 \%$ positive samples of B. burgdorferi s.l.. Results of DNA detection of tularemia, leptospirosis and Lyme borreliosis were obtained on already known enzootic territories as well as on new ones. During the investigation of soil samples collected from burial places of animals, DNA of B.anthracis were not detected. Also, results of PCR-tested samples of ticks and rodents were negative and did not confirm the presence of C. burnetii. Based on data received from PCR analysis, anti-epidemic measures were carried out in places where positive results were found: additional acaricidal treatment of areas of ticks breeding, deratization measures and educational work with the population. The investigation of 40 serum samples collected from people living in the enzootic territory gave negative results, but the work continues.

\section{Conclusions}

PCR methodology provides a possibility to monitor the natural foci of EDP at a fundamentally new level. Its requires less time for getting results if compared to classical methods, the level of biorisks during the work is lower, and it is possible to conduct samples at the same time to detect several pathogens.

\section{Keywords}

epidemiological surveillance; natural foci; tularemia; leptospirosis; Lyme borreliosis

\section{Acknowledgments}

Authors would like to express their gratitude to the Biological Threat Reduction Program, Cooperative Biological Engagement Program (Defense Treat Reduction Agency, USA) for their support in conducting this research.

\section{References}

1. Practical Guide for Laboratory Diagnosis of Infectious Diseases, Moscow, Meditsina Shiko Publishing House, 2009.

2. UCDCM Information Sheet as of 07/21/2010 No. 04.4-31/40/868 On Epidemic and Epizootic Situation with Zoonotic Infections Common for Humans and Animals (Tularemia, Anthrax, Brucellosis, Ornithosis, Listeriosis) and Methods of their Prevention in Ukraine.

3. Methodical recommendations "Application of polymerase chain reaction for the detection of pathogens of human infectious diseases" - Kyiv, 2003 (approved by the Ministry of Health of Ukraine).

\section{*Oksana Semenyshyn}

E-mail: lab.oni.Iviv@gmail.com 